Vol. 2, No. 1, pp. 1-10, (March 2021)

DOI: 10.21608/aujes.2021.149155

Aswan University Journal of Environmental Studies (AUJES)

Online ISSN: 2735-4237, Print ISSN: 2735-4229

Journal homepage: https://aujes.journals.ekb.eg/

Rreview article

E-mail: $\underline{\text { AUJES@aswu.edu.eg }}$

\title{
Available Recycling Solutions for Increased Personal Protective Equipment in the Environment Due to the COVID-19 Pandemic Amra Bratovcic
}

\author{
University of Tuzla, Faculty of Technology, Department of Physical Chemistry and Electrochemistry \\ Urfeta Vejzagica 8, 75000 Tuzla
}

Received: $9 / 1 / 2021$

Accepted: 8/2/2021

(C) Unit of Environmental Studies and Development, Aswan University

\begin{abstract}
:
The whole world today is facing an enormous increase in plastic waste pollution caused by the emergence of the COVID - 19 pandemic. A complex chemical composition of personal protective equipment (PPE) mainly containing polypropylene (PP) complicates the recycling process, and it could take at least 450 years to degrade. Plastic pollution was already one of the greatest threats to our planet before the coronavirus outbreak. Disposal of millions of contaminated PPEs would end up as wastes, which, if improperly managed, can generate tonnes of plastic waste and consequently plastic pollution which is a significant threat to oceans and marine life. Eight million tons of plastic waste already end up in the world's oceans every year, and the impact of COVID-19 will only increase those figures. To reduce the amount of waste after using face masks and gloves which ends up in the environment have been proposed by different waste management companies and discussed in detail. Moreover, an eco-friendly way for photocatalytic degradation of polypropylene via $\mathrm{TiO}_{2}$-based nanomaterials under solar irradiation is present. Catalytic conversion of PP is also proposed for the reduction of environmental pollution. This review aimed to provide a comprehensive overview of plastic pollution and discussing potential strategies to overcome them.
\end{abstract}

Keywords: plastic pollution, personal protective equipment (PPE), polypropylene (PP), recycling, conversion.

\section{1- INTRODUCTION}

The emergence of the novel human coronavirus (SARS-CoV-2) since December 2019 has increased the presence of face masks and medical waste in the environment, thereby demanding the urgent prevention and control of the pandemic COVID-19 (Sangkham, 2020). To stop the spread of COVID-19, the use of personal protective equipment (PPE), such as medical masks and gloves became essential by medical staff and health workers, and later on by ordinary citizens. Actually, during the pandemic, the use of single-use plastic, masks, gloves, sanitizers, has become mandatory to use in all public offices and transport, banks, stores, and health facilities. Because of these recommendations, millions of PPE are manufactured and used daily during the pandemic.

Corresponding author*: E-mail address: amra.bratovcic@untz.ba 
Consequently, the demand for PPE increased significantly worldwide and become part of our outfit. The coronavirus pandemic has irreversibly changed public life. Estimated monthly use of 129 billion face masks and 65 billion gloves would be necessary to protect citizens worldwide (Prata et al., 2020). According to various global production projections, around 52 billion masks have been manufactured in 2020 as part of pandemic prevention efforts (Gupta, 2020). The number of PPE used daily in Africa is estimated to reach seven hundred million (Nzediegwu and Chang, 2020).

It was found that 2,228,170,832 face masks were used in Asia in total and its distribution by countries is shown in diagram 1 (Sangkham, 2020).

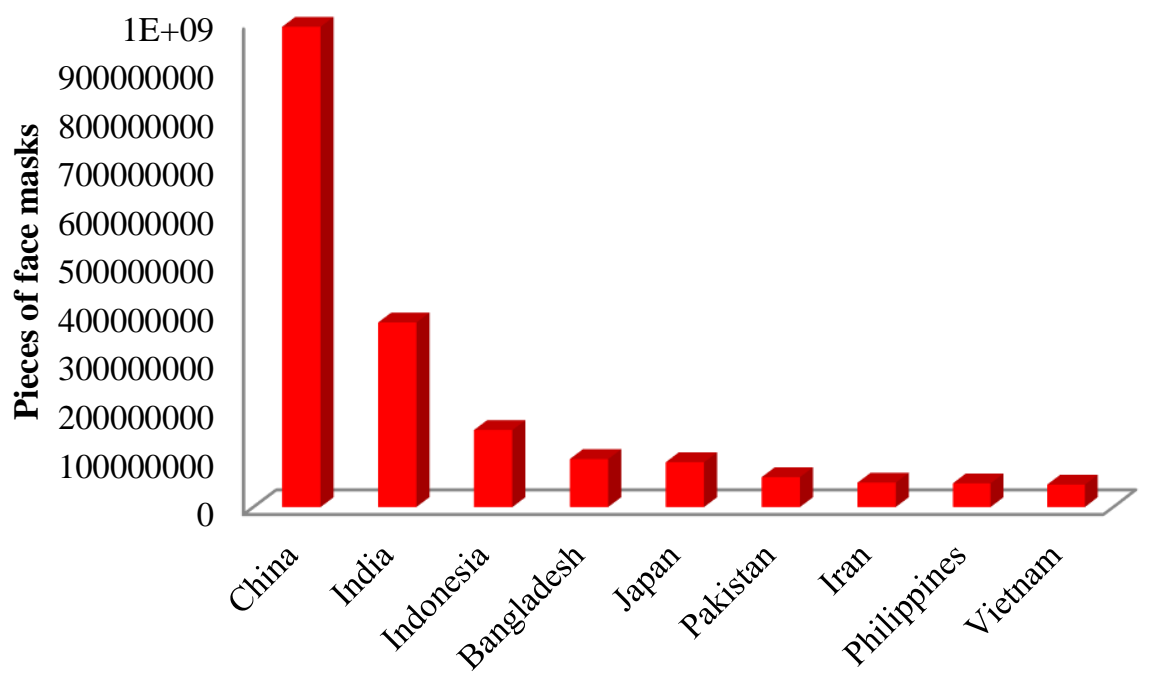

Diagram 1. The number of masks used in Asian countries (Sangkham, 2020).

From diagram 1 is evident that China uses the most daily face masks, followed by India, Indonesia, Bangladesh, Japan, Pakistan, Iran, Philippines, and Vietnam.

The quantity of total daily face mask Tripathi and co-workers estimated (Tripathi et al., 2020) by using the following equation:

where is:

$$
\text { Total daily facemask }=\frac{A \cdot B(\%) \cdot C(\%) \cdot D}{10000}
$$
A - population
B - urban population (\%)
$\mathrm{C}$ - facemask acceptance rate $(\%)$ is assumed $80 \%$
$\mathrm{D}$ - average daily face mask per capita is assumed 2.

The data used for calculation were available in the middle of August 2020 from weblink (Worldmeters, 2020).

Weight of masks (tonnes) is calculated based on each mask weighing $4 \mathrm{~g}$ (Scaraboto et al., 2020). Diagram 2 presented the estimated data of total daily facemask in million and weight of total facemask used in tonnes in Asia, Africa, Europe, North America, Oceania, and South America. 


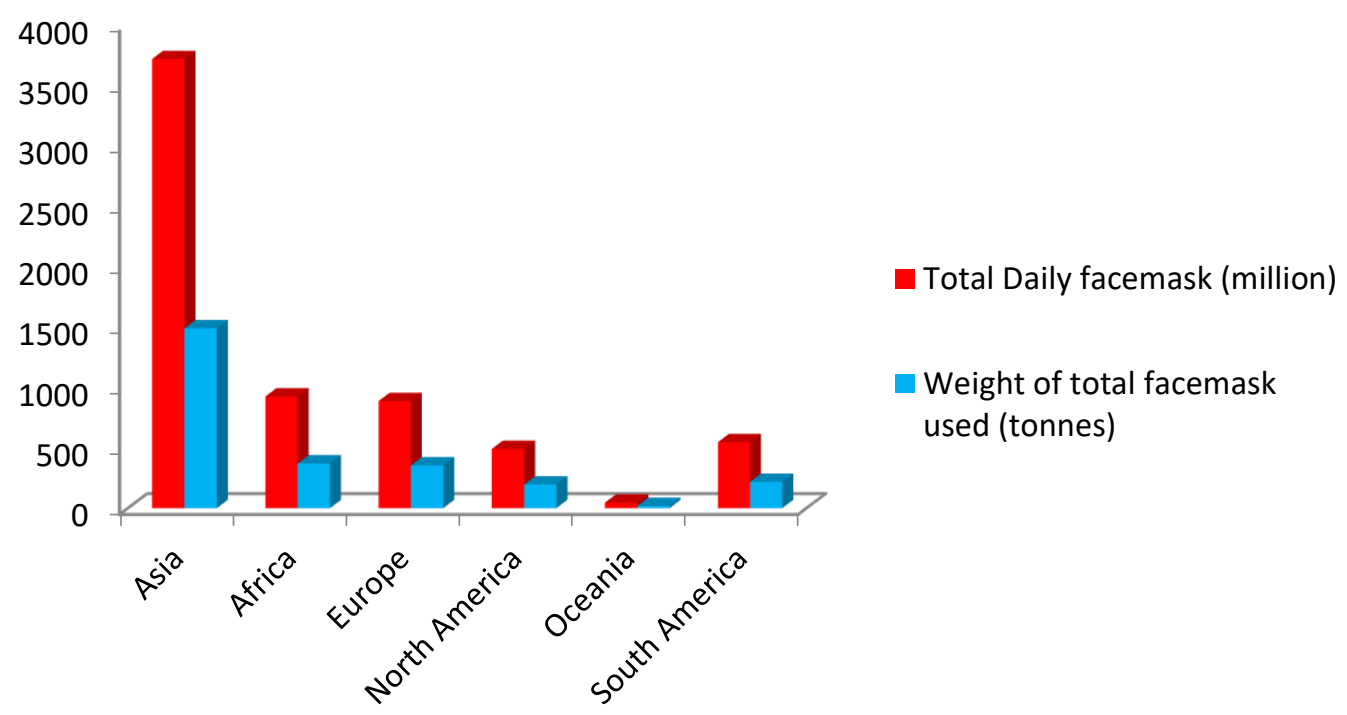

Diagram 2. The total daily facemask and weight of total facemask used in Asia, Africa, Europe, North America, Oceania, and South America (Sangkham, 2020).

Global sales of disposable face masks alone are set to skyrocket from an estimated \$ 800 million in 2019 to $\$ 166$ billion in 2020, according to business consulting firm Grand View Research (UNCTAD, 2020). The global market for disposable masks is projected to accelerate at a CAGR of $5.4 \%$ to reach US $\$ 28.8$ billion by the year 2027 . The biggest growth spikes are expected in the years 2020 and 2021 at 396.6\% and 18. 2\% CAGR respectively (Research and Markets, 2020).

Besides personal protective equipment PPE, it has been evident increased use of plastics packaging materials for take-away food (Bratovcic, 2020a). There was a reported increase in online food purchases and daily necessities by $92.5 \%$ and $44.5 \%$, respectively in South Korea relative to last year due to the COVID-19 pandemic (Hyun, 2020).

According to the Eurostat data a decrease in the plastics industry production since 2018 is observed, but in 2019 and in the first half of the year 2020 a sharp drop in production due to COVID-19 is observed. In 2019, according to PlasticsEurope (the Association of Plastics Manufacturers in Europe) and EPRO (the European Plastics Recycling and Recovery Organisations) plastic industry created a turnover of over three hundred and fifty billion euros. According to the source of PlasticsEurope Market Research Group (PEMRG) and Conversio Market \& Strategy GmbH, in 2019, global plastic production almost reached 370 million tonnes, while in Europe almost 58 million tonnes. It is predicted that the amount of plastic production as it was before the COVID-19 pandemic will be achieved only in 2022. In 2018 and 2019, five million tonnes/year were produced in European recycling facilities and $80 \%$ re-entered the European economy in order to manufacture new products (PlasticsEurope, 2020).

\section{DISPOSAL OF PPE IN THE ENVIRONMENT AND RECYCLING}

\subsection{Chemical composition of face masks}

Disposable face masks are usually made of polypropylene (PP). Polypropylene is formed by polymerization of propylene in the presence of the Ziegler-Natta or metallocene catalyst (Aguado and Serrano, 1999). PP is not biodegradable, weighing between 4,680 and 6,240 metric 
tonnes, could take at least 450 years to degrade. PP is a polymer plastic that is a member of the "polyolefin" (polymers produced from alkenes) family. It is a highly versatile and rugged material that has many beneficial physical properties, and most importantly it is also recyclable.

\subsubsection{Recycling of Polypropylene (PP)}

The mechanical recycling of plastic waste as a major current recycling process is limited by the sorting/pretreatment of plastic waste and degradation of plastics during the process. By chemical recycling of plastics which is is an alternative to mechanical processes could be produced chemical raw materials and fuels instead of the most commonly used feedstock petrochemicals (Thiounn and Smith, 2020). Depending on the complexity of the chemical composition of plastics, such as polyethylene terephthalate (PET), high-density polyethylene (HDPE), lowdensity polyethylene (LDPE)/linear low-density polyethylene (LLDPE) and PP the percentages of their recycling success differ. According to US EPA, the highest percent of PET i.e. about eighteen percent was recycled, while only ten percent of HDPE, six percent of LDPE/LLDPE, and less than one percent of PP were recycled (US EPA, 2018). The presence of the tertiary C atom in PP significantly complicates its thermal decomposition in relation to PE and is also subject to thermooxidative and photooxidative degradation (Xanthos, 2012).

The additional problem is that some PP plastics include also a stabilizer to prevent decay. In this context, if the PP polymer is successfully recycled into the new material, this material must then contain additional stabilizers to give the "newly made" material the same oxidative stability, while stabilizer accumulation and sacrificial stabilizer degradation products contribute proportionately to deterioration of PP properties.

Chen et al. found that in used supercritical water with optimal reaction conditions is possible to achieve up to $91 \mathrm{wt} \%$ of the PP conversion into the oil containing olefins, paraffins, cycloalkanes, and aromatics (Chen et al. 2019).

There are two facts that make it difficult to recycle disposable face masks; the first is the complex chemical composition of the composite; the second is the risk of contamination and infection. Based on the first fact, the Environmental Protection Department states that "they are not suitable for recycling or discarding in recycling bins, because most masks are made of composite materials that are difficult to separate, to avoid contaminating other recyclables" (Lo, 2020). The even more complex composition of polymers used by China to make face masks further complicates the recycling process (Monella, 2020).

Unfortunately, PP as one of the most commonly used materials for plastic packaging, is mostly find in landfills, because the percentage of its recycling is only 1\%. Another disadvantage is the long process of decomposition, so the time required is even between twenty and thirty years. The incineration of polypropylene, in addition to toxic heavy metals such as lead and cadmium used as additives, also releases organic toxic compounds such as dioxins and vinyl chloride, which has negative effects on human health and environmental pollution.

The separation of PP from other plastic polymers may be done in three different ways which are based on: a) the difference in specific density and is so-called sink-float separation, b) the melt flow index, and c) dissolution and reprecipitation of PP.

Due to low specific density of PP which is $0.93-0.95 \mathrm{~g} / \mathrm{cm}^{3}$ allows it to float, while PET with higher specific density of $1.43-1.45 \mathrm{~g} / \mathrm{cm}^{3}$ will sink. The PP reprocessing is carried out by melting in an extruder at a temperature higher than $204^{\circ} \mathrm{C}$. After melting, granulation is carried 
out. For the production of new clothes or playground equipment a mixture of recycled and raw polypropylene up to $50 \%$ is usually used (Thomas, 2020).

\subsection{Impact of PPE on the environment}

Recently, Kampf and co-workers find that on material surfaces such as metals, glass, and plastics the coronavirus can survive for up to 9 days (Kampf et al., 2020). Even more concerning is that improper management of used PPEs can pose a significant risk for increasing the transmission of COVID-19. The danger of plastic waste reaching the environment explains the process of degradation of plastic to microplastic. Thus, the gradual process of decomposition of plastic waste creates microplastics that directly reach the digestive tract of sea creatures, directly disrupting their health, and then indirectly by their consumption and human health (Bratovcic, 2019 a). Statistics indicate negative impacts on fisheries and the tourism industry. It has been estimated that plastic pollution kill 100,000 marine mammals and turtles, over a million seabirds, and even greater numbers of fish, invertebrates, and other animals each year which costs $\$ 13$ billion for the global economy.

\subsubsection{Disposal of PPE}

Single-use plastic has surged in production in recent decades, filling up oceans and land with waste and overwhelming the capability of waste management systems across the world to dispose of and recycle the plastics. According to a new report, "Breaking the Plastic Wave", about 710 million metric tons of plastic will be dumped into the environment by 2040 (Newburger, 2020). The amount of plastic trash that flows into the oceans every year is expected to nearly triple by 2040 to 29 million metric tons (Parker, 2020).

For example, in Wuhan, China, hospitals generated more than six times waste per day during the peak of the COVID-19, or more precisely instead of 40 tons per day at normal times, it is now 240 tons per day. In the USA, it is estimated that this ratio could also be 6 times higher, i.e. that the amount of medical waste that was normally related to one year would be generated within two months. At the time of the pandemic, people were ordering more food to be delivered to their homes, which meant increased use of plastic packaging material. There are also indications that during the pandemic, the illegal way of disposing of plastic waste increased by $280 \%$ worldwide. A particular problem is the fact that despite the increase in production and consumption of plastic materials, recycling rates have not increased but even decreased. There are major concerns that due to the specific working hours, shift schedules and respect for spatial distance, they could affect waste management and thus generate increasing amounts of waste ending up in landfills (ReportLinker, 2020).

\subsubsection{Correctly disposal of face masks}

The outbreak and spread of the COVID-19 pandemic, among other challenges, brought the issue of the handling and safe disposal of COVID-19 waste generated from the households and medical care facilities. If improperly COVID-19 waste is collected or treated, it may accelerate disease spread and pose a significant risk to medical staff, patients, and waste collection and treatment staff. In order to avoid cross-contamination, surgical masks and gloves should be adequately discarded and should not be worn longer than a few hours. In this sense, fewest countries have tried to implement safety measures considering the disposal of potentially infected PPE (Patricio Silva, 2021). 
According to Ipswich Borough Council, surgical face masks and gloves can be disposed of in the normal general/black bin waste. This approach is aligned to guidance from Public Health (England, Scotland \& Wales) and has been confirmed with regulators (the Environment Agency, the Scottish Environment Protection Agency \& Natural Resources Wales) (NREB20-02. 2020).

Black bin is for general rubbish such as crisp packets, used nappies, food waste, and items like Tetrapak (Ipswich Borough Council, 2021).

In order to minimize possible secondary impacts upon health and the environment from COVID19 waste in Bosnia and Herzegovina, Sweden, through United Nations Development Programme (UNDP), has supported authorities with an effective response and educating citizens on how to handle this type of waste (UNDP, 2020).

According to the recommendations of the World Health Organization (WHO), face masks and gloves used to combat the pandemic after use should not be mixed with other waste, i.e. it should not be disposed of in bins intended for the recycling of packaging, cans or organic waste, but in special bins. They must be separated from general household rubbish.

Unlike the WHO, the Brazilian Sanitary and Environmental Engineering Association (ABES) nevertheless advises that used masks and gloves should be packed in two plastic bags, tied tightly and thrown away along with household waste. In addition, they advised that if masks and gloves were used by persons infected with coronavirus, that the bags must indicate the "risk of contamination" (Iberdrola, 2020).

The Portuguese Environmental Agency recommended, similar to ABES, that all potentially contaminated masks and gloves used by citizens be disposed of as mixed waste that cannot be recycled in closed garbage bags and which are likely to be disposed of in incinerators or in a daily landfill (Ambiente, 2020).

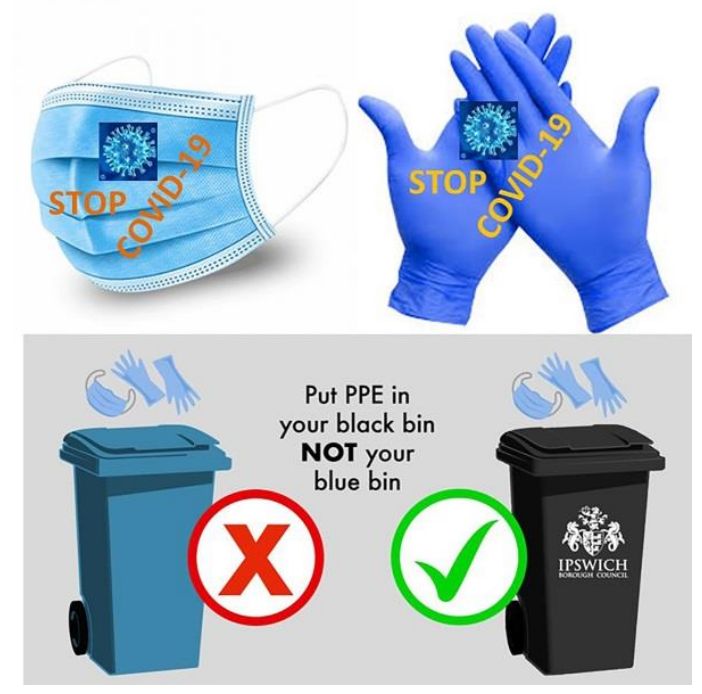

Fig. 1 Correct disposal of PPE against Coronavirus (COVID-19) such as face masks and gloves in the normal general/black bin waste according to (NREB20-02. 2020).

New solutions to reduce the negative impact of face masks on the environment are discussed and one of them is also to use the organic, biodegradable masks with cotton, linen, bamboo, silk, and hemp face coverings all currently being marketed widely. 
This paper reviews the plastic waste generation due to the COVID-19 pandemic and discusses how waste can be handled or recycled to reduce disease spread. It also provides examples taken by various companies on how to manage solid waste during the COVID-19 pandemic.

\subsection{Problems for recycling PPE}

Waste management crews have seen a surge in items like gloves, masks, and gowns placed in recycling carts when they actually belong in the trash. According to the Metropolitan Water Reclamation District of Greater Chicago disposable wipes, paper towels, and tissues that people have been using to sanitize surfaces also are not recyclable, and never have been. Moreover, they state that these items weren't flushable, either, even if their packaging claims that they are. To-go food containers with the No. 6 label aren't recyclable, nor is plastic serve ware (Wetli, 2020).

The toxicity of PP incineration has been mentioned earlier in the text, so that any uncontrolled incineration of medical waste made of plastic is not recommended due to contributes to the release of greenhouse gases, dioxins, PCBs, and furans (Heidari et al., 2019).

\subsection{Recycling solution for PPE}

Waste management company TerraCycle has launched zero-waste boxes to collect and recycle PPE, face masks, and disposable gloves. The company offers the Disposable Gloves EasyPak Box to recycle vinyl, nitrile, and latex gloves and the Disposable Masks EasyPak Box to recycle surgical and industrial face masks. Collected materials can be cleaned, melted, and remolded to make new products (Taylor, 2020).

French start-up Plaxtil was initially set up to turn textiles into the plastic. But since mid-June 2020, it has up-cycled thousands of face masks. After the metal noseband is removed, the material is ready to use, which is then disinfected as it passes through ultra-violet light. It is then pressed into plastic and molded into new types of protective equipment - from visors to attachments to help hold masks in place (KOIN 6 News Staff, 2020).

ReWorked used innovative technology to reduce the amount of waste PPE that ends up in our natural environments. They create a product called Stormboard from standard disposable masks made from PP. One of the innovative creations is the sanitizer bin - ideal for collecting more used PPE \& dispersing sanitizer to customers or employees which completely "closes the loop" when it comes to minimizing the environmental damage to the pandemic (Maltings, 2020).

The solution to incinerate masks is not good because of the level of $\mathrm{CO}_{2}$ emissions generated. Removal of toxic organic compounds from water by adsorption with porous materials such as carbon aerogels and xerogels was considered as one of the most efficient techniques without any secondary pollution (Bratovcic and Petrinic, 2020). Lerici et al. in 2015 carried out termocatalytic degradation of polypropylene on the H-Y zeolite. The catalytic activity was carried out in a batch reactor at $500{ }^{\circ} \mathrm{C}$ for $43,75 \mathrm{~min}$. Liquid product yield was $\sim 44 \% \mathrm{wt} \%$, while the gaseous products $\sim 52 \mathrm{wt} \%$. The PP generated the greatest amount of carbonaceous residues ( 10 wt $\%)$.

In recent research (Bratovcic, 2019b) was discussed photocatalytic degradation of micro- and nano-plastics. Verma and co-workers reveal a photocatalytic way for the degradation of the PP polymer with the assistance of $\mathrm{TiO}_{2}$-based nanomaterials and $\mathrm{TiO}_{2}$-rGO nanocomposite under solar irradiation for $130 \mathrm{~h}$ in a triplicate manner (Verma et al. in 2017). Structural and microstructural investigations elucidate the effective augmentation of PP photodegradation by $\mathrm{TiO}_{2}$-rGO nanocomposite as evaluated by calculating carbonyl index and the appearance of cavity formation of $\sim 500 \mathrm{~nm}$ diameter via FT-IR and FE-SEM spectroscopy, respectively. The 
mechanism of photocatalytic degradation of organic compounds has been discussed in detail (Bratovcic, 2019c).

\section{Conclusion}

The trend of increasing the use of plastic materials has been recorded from year to year, and thus a huge increase in plastic waste. The use of disposable plastic materials such as plastic packaging materials, gloves and masks increased especially during the pandemic COVID-19 and as a consequence additionally generated a huge amount of plastic waste material that requires a special method of disposal. Most plastic waste is disposed of in landfills or incinerated, which has a negative impact on human health and the environment. Taking into account only the amount of masks and gloves used daily to prevent the spread of coronavirus will undoubtedly exceed the current estimates of 4-12 million tons of plastic that goes to the seas and oceans annually. One of the possible quick current solutions to reduce plastic waste in the environment is the use of a biodegradable reusable mask. In addition, there is an urgent need to adapt the medical waste management strategy for the COVID-19 pandemic to reduce the risk of the pandemic spreading to the environment.

\section{References}

Aguado, J. and Serrano, D.P. (1999), in Feedstock Recycling of Plastic Wastes (Ed: J. H. Clark), The Royal Society of Chemistry, Cambridge, $p .1$.

Ambiente, A.P. (2020). Gestao de residuos em situacao de pandemia por SARS-CoV-2 (COVID19) [Waste management in a pandemic by SARS-VoV-2 (COVID-19]. https://apambiente.pt/_zdata/Instituicao/Impresa/2020/Nota_OCS_2020-

19_GestaoResiduos_SituacaoPandemia,pdf.

Bratovcic, A. (2019a). Different applications of nanomaterials and their impact on the environment, SSRG - Int. J. Mater. Sci. Engin. 5(1): 1-7.

Bratovcic, A. (2019b) Degradation of Micro- and Nano-Plastics by Photocatalytic Methods. J Nanosci Nanotechnol Appl. 3: 304.

Bratovcic, A. (2019c). Photocatalytic degradation of organic compounds in wastewaters. Technologica Acta. 11(2): 17-23.

Bratovcic, A. (2020a). Nanomaterials in Food Processing and Packaging, its Toxicity and Food Labeling. Acta Scientific Nutritional Health (ASNH). 4(9): 07-13.

Bratovcic, A. and Petrinic, I. (2020). Carbon based aerogels and xerogels for removing of toxic organic compounds. In: Karabegović I. (eds) New Technologies, Development and Application III. NT 2020. Lecture Notes in Networks and Systems. vol 128. Springer, Cham.

Chen, W.-T. Jin, K., Linda Wang, N.-H. (2019). Use of Supercritical Water for the Liquefaction of Polypropylene into Oil. ACS Sustain. Chem. Eng. 7(4): 3749-3758.

Gupta, A. (2020). https://news.cgtn.com/news/2020-12-08/Tsunami-of-1-56-billion-maskstriggers-new-wave-of-marine-pollution-W3jOBoX5cY/index.html (Accessed 3 January 2021).

Heidari, M., Garnaik, P.P., Dutta, A. (2019). The Valorization of Plastic Via Thermal Means: Industrial Scale Combustion Methods. in: S.M. Al-Salem (Ed.). Plastics to Energy. William Andrew Publishing., 295-312. 
Hyun, M.C. (2020). Korea sees steep rise in online shopping during COVID-19 pandemic. ZD Net. https://www.zdnet.com/article/korea-sees-steep-rise-in-online-shopping-during-covid19-pandemic/ (Accessed 4 January 2021).

Iberdrola (2020). https://www.iberdrola.com/social-commitment/how-to-dispose-of-face-masks. (Accessed 4 January 2021).

Ipswich Borough Council. https://www.ipswich.gov.uk/yourbins. (Accessed 6 January 2021).

Kampf, G., Todt, D., Pfaender, S., Steinmann, E. (2020). Persistence of coronaviruses on inanimate surfaces and their inactivation with biocidal agents. J. Hospital Infect. 104 (3): 246-251.

KOIN 6 News Staff. (2020). https://www.koin.com/news/health/coronavirus/french-companyworks-to-recycle-masks-into-ppe/. (Accessed 4 January 2021).

Lerici, L.C., Renzini, M.S., Pierella, L.B. (2015). Chemical Catalyzed Recycling of Polymers: Catalytic Conversion of PE, PP and PS into Fuels and Chemicals over H-Y. Procedia Mater. Sci. 8: 297 - 303.

Lo, Z. (2020). https://hk.asiatatler.com/life/covid-19-face-masks-pollution. (Accessed 4 January 2021).

Maltings. (2020). https://www.maltingsorganic.com/news/reclaim-the-mask-ppe-recycling/. (Accessed 4 January 2021).

Monella, L.M. (2020). Will plastic pollution get worse after the COVID-19 pandemic?. Euronews. https://www.euronews.com/2020/05/12/will-plastic-pollution-get-worseafterthe-covid-19-pandemic. (Accessed 4 January 2021).

Newburger, E. (2020). Enormous amount of plastic will fill oceans, land by 2040 even with immediate global action. https://www.cnbc.com/2020/07/23/enormous-amount-of-plastic-will-fill-oceans-and-landby-2040-report.html. (Accessed 7 January, 2020).

NREB20-02 (2020). Corona virus waste: disposal of face masks, Environment bulletin. https://safety.networkrail.co.uk/wp-content/uploads/2020/06/Environment-BulletinNREB20-02-Coronavirus-COVID-19-Waste-Disposal-of-face-masks.pdf. $\quad$ (Accessed 6 January 2021).

Nzediegwu, C., Chang, S.X. (2020). Improper solid waste management increases potential for COVID-19 spread in developing countries. Resources, Conservation \& Recycling. 161. 104947.

Parker, L. (2020). Plastic trash flowing into the seas will nearly triple by 2040 without drastic action. National Geographic. https://www.nationalgeographic.com/science/2020/07/plastictrash-in-seas-will-nearly-triple-by-2040-if-nothing-done/ (Accessed 6 January, 2020).

Patricio Silva, A.L., Prata, J.C., Walker, T.R., Duarte, A.C., Ouyang, W., Barcelo, D., RochaSantos, T. (2021). Increased plastic pollution due to COVID-19 pandemic: Challenges and recommendations. Chem. Engin. J. 405. 126683.

PlasticsEurope. (2020). Plastics - $\quad$ (the 2020. https://www.plasticseurope.org/en/resources/publications/4312-plastics-facts-2020 (Accessed 7 January 2020). 
Prata, J.C., Silva, A., Walker, T.R., Duarte, A.C., Rocha-Santos, T.A.P. (2020). COVID-19 Pandemic Repercussions on the Use and Management of Plastics. Environ. Sci. Technol. 54: $1-6$.

ReportLinker (2020). https://www.globenewswire.com/newsrelease/2020/11/19/2130106/0/en/Global-Plastic-Recycling-Industry.html.

Research and Markets (2020). https://www.globenewswire.com/newsrelease/2020/09/11/2092580/0/en/Global-Disposable-Masks-Market-Report-2020-2027Biggest-Market-Growth-Spikes-are-Expected-in-2020-and-2021-at-396-6-and-18-2.html.

Sangkham, S. (2020). Face mask and medical waste disposal during the novel COVID-19 pandemic in Asia. Case Studies Chem. Environ. Eng. 2. 100052.

Scaraboto, D., Joubert, A.M., Gonzalez-Arcos, C. (2020). Single-use plastic in the pandemic: how to stay safe and sustainable. World Economic Forum. https://www.weforum.org/agenda/2020/04/plastic-packaging-coronavirus-crisis/, (Accessed 5 January 2020).

Taylor, B. (2020). https://www.recyclingtoday.com/article/terracycle-ppe-recycling-easypakcontainers/. (Accessed 4 January 2021).

Thiounn, T. and Smith, R.C. (2020). Advances and approaches for chemical recycling of plastic waste. J Polym Sci. 58:1347-1364.

Thomas. G.P. (2020). https://www.azocleantech.com/article.aspx?ArticleID=240. (Accessed 5 January 2021).

Tripathi, A., Kumar Tyagi, V., Vivekanand, V., Bose, P., Suthar, S. (2020). Challenges, opportunities and progress in solid waste management during COVID-19 pandemic. Case Studies Chem. Environ. Engin. 2. 100060.

UNCTAD (2020). https://unctad.org/news/growing-plastic-pollution-wake-covid-19-how-tradepolicy-can-help (Accessed 3 January 2021).

UNDP (2020). Sweden supports Bosnia and Herzegovina authorities with management of COVID-19

waste. https://www.ba.undp.org/content/bosnia_and_herzegovina/en/home/presscenter/articles/20 20/COVID-19otpad.html. (Accessed 5 January 2021).

US EPA, 2018. EPA530-F-18-004. Advancing Sustainable Materials Management: 25Fact Sheet Assessing Trends in Material Generation, Recycling, Composting, Combustion with Energy Recovery and Landfilling in the United States. 1-22.

Verma, R., Singh, S., Dalai, M.K., Saravanan, M., Agrawal Ved, V., Kumar Srivastava, A. (2017). Photocatalytic degradation of polypropylene film using $\mathrm{TiO}_{2}$-based nanomaterials under solar irradiation. Materials \& Design. 133: 10-18.

Wetli, P. (2020). https://news.wttw.com/2020/04/14/coronavirus-related-gloves-masks-andwipes-don-t-belong-recycling. (Accessed 4 January 2021).

Worldometers (2020). https://www.worldometers.info/coronavirus/ (Accessed 5 January 2021).

Xanthos, M. (2012). Recycling of the \#5 Polymer. Science (Washington, DC, U. S.) 337 (6095): $700-702$. 